\title{
ANALISIS DAMPAK PANDEMI COVID-19 TERHADAP SUSTAINABILITY PADA INDUSTRI KECIL DAN MENENGAH DENGAN METODE ANALYTICAL HIERARCHY PROCESS (AHP)
}

\author{
Andi Besse Riyani Indah* \\ Program Studi Teknik Industri, Universitas Hasanuddin, Gowa, Indonesia \\ Nadzirah Ikasari \\ Program Studi Teknik Industri, Universitas Hasanuddin, Gowa, Indonesia \\ Dian Pratiwi Sahar \\ Program Studi Teknik Industri, Universitas Pattimura, Ambon, Indonesia \\ *E-mail korespondensi: a.besseriyani@gmail.com
}

\begin{abstract}
ABSTRAK
IKM di Indonesia mulai berkembang dengan berbagai jenis usaha khususnya di Kota Makassar. Dalam menjalankan usahanya setiap IKM dituntut untuk mempertahankan keberlanjutan (sustainability) usahanya. Sustainability merupakan hal yang perlu diperhatikan jika IKM ingin tetap bertahan dan bersaing dalam skala lokal, nasional, hingga internasional. Sustainability mencakup tiga aspek utama yaitu ekonomi, lingkungan, dan sosial. Dimasa pandemi Covid-19 beberapa IKM mengalami permasalahan dalam menjalani usahanya, dan hal tersebut menyebabkan beberapa IKM tidak dapat mencapai target sustainability. Berdasarkan permasalahan ini maka dilakukan penelitian untuk melakukan analisis dampak pandemi Covid-19 terhadap sustainability pada IKM khususnya di Kota Makassar. Tujuan dari penelitian ini akan diketahui aspek sustainability yang tidak dapat dicapai secara maksimal oleh IKM karena dampak dari pandemi Covid-19. Analisis dilakukan dengan menggunakan metode Analytical Hierachy Process (AHP). Metode AHP merupakan metode yang digunakan untuk membantu menyusun suatu prioritas dari berbagai pilihan dengan menggunakan beberapa kriteria (multi criteria). Berdasarkan data yang diolah dengan AHP kriteria dengan tingkat kepentingan yang tinggi adalah kriteria ekonomi dengan priority vector sebesar 0.63, sedangkan berdasarkan hirarki alternatif pada masing-masing kriteria diperoleh hasil bahwa Kesehatan dan keselamatan (sosial) dengan priority vector sebesar 0.36, kurangi penggunaan energi (lingkungan) dengan priority vector sebesar 0.40, dan keuntungan (ekonomi) dengan priority vector sebesar 0.48 merupakan alternatif yang memiliki nilai kepentingan tertinggi.
\end{abstract}

Kata Kunci: IKM; Sustainability; Pandemi Covid-19; Analytical Hierachy Process (AHP); Sustainability policy.

\begin{abstract}
SMEs in Indonesia are starting to develop with various types of businesses, especially in Makassar City. In support of every SMEs victory to maintain (sustainable) development. Sustainability is something that needs to be considered if SMEs want to survive and compete on a local, national and international scale. Sustainability includes three main aspects, namely economic, environmental and social. During the Covid-19 pandemic, several SMEs experienced problems in running their businesses, and this caused some SMEs to be unable to achieve their sustainability targets. Based on this problem, a research was conducted to analyze the impact of the sustainability of the Covid-19 pandemic on SMEs, especially in Makassar City. The purpose
\end{abstract}


of this research will be to find out aspects of sustainability that cannot be achieved optimally by SMEs due to the impact of the Covid-19 pandemic. The analysis was carried out using the Analytical Hierachy Process (AHP) method. The AHP method is a method used to help develop a priority from various options using several criteria (multi-criteria). Based on the data processed by AHP, the criteria with a high level of importance are the economic criteria with a priority vector of 0.63 , while based on the alternative hierarchy on each criterion, the result is that Health and safety (social) with a priority vector of 0.36 , reduces energy use (environmental) with a priority vector of 0.40 , and the benefits (economy) with a priority vector of 0.48 are alternatives that have the highest importance value.

Keywords: SMEs; Sustainability; Covid-19 pandemic; Analytical Hierarchy Process (AHP); Sustainability policy.

\section{PENDAHULUAN}

Indutri Kecil dan Menengah (IKM) merupakan salah satu pendongkrak bagi sector perekonomian di Indonesia. Salah satu yang menjadi keunggulan IKM adalah mampu menyerap tenaga kerja yang sangat besar, karena pada dasarnya IKM tidak membutuhkan kualifikasi pendidikan tertentu dalam menjalankan kegiatan produksi dan usahanya. Oleh karena itu, keberlanjutan (sustainability) IKM menjadi hal yang sangat penting untuk terus meningkatkan kemampuan IKM dalam bersaing secara local, nasional, hingga internasional. Menurut (Setiyadi, Amar, \& Aji, 2011) IKM harus mampu memiliki kecakapan manajerial, dan mengetahui teknik menjual yang strategis yang dimulai dari pengetahuan tentang produk, ciri khas produk dan daya saing produk terhadap produk sejenis. Hal ini dilakukan agar IKM mampu memasarkan setiap produk yang dihasilkan dengan baik dan produk yang telah dihasilkan dapat bertahan walaupun berada pada persaingan yang ketat.

Sustainability merupakan suatu konsep yang diterapkan dalam perusahaan agar suatu perusahaan dapat mencapai keberlanjutan dalam usahanya untuk waktu jangka Panjang. Terdapat tiga aspek dalam sustainability yaitu ekonomi, lingkungan, dan sosial. Ketiga aspek ini merupakan hal yang mendasar yang harus dicapai perusahaan termasuk IKM agar mencapai target sustainability. Adapun ekonomi mengarah pada proses produksi yang dilakukan sebisa mungkin mencapai efisiensi termasuk dalam hal bahan baku, tenaga kerja, dan biaya produksi. Pada aspek lingkungan, dalam proses usahanya harus dipastikan bahwa kegiatan yang dilakukan tidak memberi dampak negatif terhadap lingkungan seperti pencemaran dan limbah berbahaya yang dihasilkan. Sedangkan pada aspek sosial mengarah pada keberlanjutan sosial sebagai sistem yang mampu mencapai kesetaraan, menyediakan layanan sosial termasuk kesehatan, pendidikan, gender, dan akuntabilitas politik.

Pandemi Covid-19 memberi dampak yang besar bagi IKM di Indonesia termasuk di Kota Makassar. Menurut data Kementerian Perindustrian RI tahun 2020 bahwa selama pandemi Covid-19 IKM mengalami penurunan permintaan terhadap produk-produk yang dihasilkan hingga 90\%, yang pada tahun sebelum pandemi Covid-19 segala aktivitas penjualan sebesar 97\% dilakukan secara offline. Dampak tersebut juga mempengaruhi ketercapaian sustainability bagi IKM yang terdiri dari aspek ekonomi, lingkungan, dan sosial. Beberapa IKM tidak dapat memenuhi target kinerjanya dalam hal sustainability. Dari sisi ekonomi mengalami masalah seperti meningkatnya biaya produksi, tenaga kerja, dan bahan baku. Dari sisi lingkungan misalnya sistem yang berwawasan lingkungan dituntut untuk mampu menjaga kestabilan sumber daya, menghindari eksploitasi sumber daya alam dan fungsi lingkungan. Sedangkan pada sisi sosial, berdampak pada kesejahteraan tenaga kerja yang terlibat pada IKM, secara langsung terdapat perubahan yang mendasar khususnya bagi para tenaga kerja IKM selama pandemi Covid-19 terutama dalam hal kesejahteraan pegawai.

Berdasarkan masalah yang telah diuraikan maka akan dilakukan penelitian analisis dampak pandemi Covid-19 sustainability pada IKM dengan metode Analytical Hierachy Process 
(AHP). Tujuan dari penelitian ini akan diketahui aspek sustainability yang terdampak pandemi Covid-19 yang terdiri dari aspek ekonomi, lingkungan, dan sosial. Metode AHP adalah metode yang digunakan untuk membantu menyusun suatu prioritas dari berbagai pilihan dengan menggunakan beberapa kriteria (multi criteria). Dengan metode AHP akan diperoleh prioritas faktor yang mempengaruhi aspek sustainability sehingga IKM tidak dapat mencapai target sustainability yang telah ditetapkan. Dari hasil analisis berdasarkan metode AHP akan dibuat rumusan usulan kebijakan dalam bentuk sustainability policy yang dapat dilakukan oleh IKM untuk mencapai aspek sustainability khususnya yang terkena dampak pandemi Covid-19.

\section{BAHAN DAN METODE}

\section{a. Industri Kecil dan Menengah (IKM)}

Menurut Peraturan Menteri Perindustrian Republik Indonesia Nomor: 13/MIND/PER/2/2013 Tentang Petunjuk Teknis Program Restrukturisasi Mesin dan/atau Perlatan Industri Kecil Menengah Pasal 1 ayat (1), (2), dan (3) yang menyebutkan:

(1) Industri Kecil dan Menengah (IKM) adalah perusahaan industri kecil dan perusahaan industri menengah.

(2) Perusahaan Industri Kecil (IK) adalah perusahaan industri dengan nilai investasi seluruhnya sampai dengan Rp. 500.000.000 (lima ratus juta Rupiah), dengan tidak termasuk tanah dan bangunan tempat usaha.

(3) Perusahaan Industri Menengah (IM) adalah perusahaan industri dengan nilai investasi seluruhnya lebih besar dari Rp. 500.000 .000 (lima ratus juta Rupiah) sampai dengan paling banyak 10.000.000.000 (sepuluh milyar Rupiah), tidak termasuk tanah dan bangunan tempat usaha.

IKM adalah bentuk kegiatan yang didalamnya tidak hanya sebatas usaha jual beli, tetapi juga ada kegiatan proses produksi dengan menggunakan teknologi, manajemen organisasi sederhana, dan kerjasama dengan pihak lain (Asmara \& Rahayu, 2014).

Menurut Undang-Undang Nomor 5 Tahun 1984 tentang Perindustrian dijelaskan bahwa industri kecil adalah kegiatan ekonomi yang terdiri dari kegiatan mengolah bahan mentah, bahan baku, barang setengah jadi, dan atau barang jadi menjadi barang yang memiliki nilai lebih tinggi penggunaannya (Ridwan, Hartutiningsih, \& Mass'ad, 2014).

\section{b. IKM selama Pandemi Covid-19}

Pandemi COVID-19 yang terjadi saat ini mau tidak mau memberikan dampak terhadap berbagai sektor. Pada tataran ekonomi global, pandemi COVID-19 memberikan dampak yang sangat signifikan pada perekonomian domestik negara-bangsa dan keberadaan UMKM. Laporan Organisation for Economic Co-operation and Development (OECD) menyebutkan bahwa pandemi ini berimplikasi terhadap ancaman krisis ekonomi besar yang ditandai dengan terhentinya aktivitas produksi di banyak negara, jatuhnya tingkat konsumsi masyarakat, hilangnya kepercayaan konsumen, jatuhnya bursa saham yang pada akhirnya mengarah kepada ketidakpastian.

Indonesia yang didominasi oleh keberadaan Usaha Mikro, Kecil, dan Menengah (UMKM) sebagai tulang punggung perekonomian nasional juga terdampak secara serius tidak saja pada aspek total produksi dan nilai perdagangan akan tetapi juga pada jumlah tenaga kerja yang harus kehilangan pekerjaannya karena pandemi ini. Data dari Kementerian Koperasi dan Usaha Kecil Menengah (KemenkopUKM) menunjukkan bahwa pada tahun 2018 terdapat 64.194.057 UMKM yang ada di Indonesia (atau sekitar 99 persen dari total unit usaha) dan mempekerjakan 116.978.631 tenaga kerja (atau sekitar 97 persen dari total tenaga kerja di sektor ekonomi).

Pada aspek perusahaan, pandemi ini telah mengganggu kinerja perusahaan-perusahaan terutama yang bergerak dalam sektor perdagangan, transportasi, dan pariwisata. Kebijakan social distancing yang kemudian diubah menjadi physical distancing dan bekerja dari atau di rumah berdampak pada penurunan kinerja perusahaan yang kemudian diikuti oleh pemutusan hubungan kerja. Bahkan ada beberapa perusahaan yang mengalami kebangkrutan dan akhirnya memilih untuk menutup usahanya. Pada aspek UMKM, adanya pandemi ini menyebabkan 
turunnya kinerja dari sisi permintaan (konsumsi dan daya beli masyarakat) yang akhirnya berdampak pada sisi suplai yakni pemutusan hubungan kerja dan ancaman macetnya pembayaran kredit (Pakpahan, 2020).

\section{c. Sustainability IKM}

Terminologi keberlanjutan sangat multiface dan originalitas dari keberlanjutan (sustainability) yang bersifat sangat komplek (Bell, S \& Morse, S., 2008). Keberlanjutan dapat menjadi sumber daya strategis yang mengarah pada keunggulan kompetitif, dan pada gilirannya, kinerja organisasi yang unggul.Sementara sebagian besar studi keberlanjutan melihat ketiga aspek dari triple bottom line, berdasarkan beberapa literatur menunjukkan hasil yang tidak meyakinkan ketika strategi bertujuan untuk menangani ketiga pendekatan keberlanjutan secara bersama-sama (Leea, Che-Haa, \& Alwi, 2019).

Dalam beberapa tahun terakhir, perhatian yang cukup besar telah difokuskan pada topik keberlanjutan yang mengintegrasikan dan menemukan keseimbangan antara aspek lingkungan, ekonomi dan sosial perusahaan. Ekonomi bersama aspek sosial dan lingkungan adalah konstruksi utama dari keberlanjutan, tetapi terkadang dari ketiga aspek ini juga cenderung saling bertentangan (Tajbakhsh \& Hassini, 2015). Keberlanjutan bisnis paling sering disajikan secara terintegrasi, menggabungkan ketiga aspek tersebut, karena sebagiannya tumpang tindih. Secara grafis, hal ini dapat digambarkan dengan tiga lingkaran yang saling tumpang tindih, dimana perpotongan di tengahnya merepresentasikan keberlanjutan (Stopper, Kossik, \& Gastermann, 2016).

Para pelaku UMKM berusaha menerapkan keberlanjutan perusahaan dengan mematuhi kebijakan dan peraturan (Witjes, Vermeulen, \& Cramer, 2017). UKM berusaha untuk mencapai keberlanjutan dengan melakukan manufaktur ramping, manufaktur hijau, dan praktik keberlanjutan lainnya. Ada temuan yang kontradiktif tentang korelasi antara praktik sosial dan lingkungan dengan keberlanjutan perusahaan dan kinerja ekonomi UKM. Praktik keberlanjutan adalah praktik apa pun yang bertujuan untuk mencapai atau mendukung nilai berkelanjutan (Phan \& Kim, 2019). Kinerja keberlanjutan dapat didefinisikan sebagai kinerja perusahaan dalam semua dimensi dan untuk semua pendorong keberlanjutan perusahaan (Malesios, De, Moursellas, Dey, \& Evangelinos , 2020).

\section{d. Sustainability IKM}

Proses Hierarki Analitik (Analytical Hierarchy Process - AHP) dikembangkan oleh Dr.Thomas L. Saaty dari Wharton School of Bussiness pada tahun 1970-an untuk mengorganisasikan informasi dan judgement dalam memilih alternatif yang paling disukai.

Perbandingan dilakukan berdasarkan "judgment" dari pengambil keputusan dengan menilai tingkat kepentingan suatu elemen dibandingkan elemen lainnya. Dibawah ini merupakan penetapan skala kuantitatif satu sampai sembilan untuk menilai perbandingan tingkat kepentingan suatu elemen terhadap elemen lain (Saaty, 1988)

Analytical Hierarchy Process digunakan sebagai metode pemecahan masalah dibanding dengan metode yang lain karena alasan-alasan berikut (Munthafa \& Mubarok, 2017):

1. Struktur yang berhierarki, sebagai konsekuensi dari kriteria yang dipilih, sampai pada sub kriteria yang paling dalam.

2. Memperhitungkan validitas sampai dengan batas toleransi inkonsistensi sebagai kriteria dan alternatif yang dipilih oleh pengambil keputusan. Memperhitungkan daya tahan output analisis sensitivitas pengambilan keputusan.

\section{e. Pengumpulan Data}

Metode pengumpulan data yang digunakan untuk memperoleh data dalam penulisan proposal penelitian ini adalah:

1. Penelitian lapangan yaitu bentuk penelitian dengan cara observasi langsung dilapangan, dengan menyebarkan kuisioner dan wawancara langsung dengan para expert dalam bidang IKM di Kota Makassar. 
2. Penelitian kepustakaan yaitu studi literatur yang berhubungan dengan masalah yang akan dibahas pada penelitian ini seperti sustainability pada IKM, dampak pandemi Covid-19 terhadap IKM, dan metode AHP.

\section{f. Pengolahan Data dan Analisis Data}

Metode pengolahan data yang digunakan pada penelitian ini adalah melakukan pengolahan data hasil kuisioner dan wawancara yang telah disebar dengan analisis deskriptif. Dan mencari nilai prioritas dari aspek sustainability yang terdiri dari aspek ekonomi, lingkungan, dan sosial yang dijadikan sebagai kriteria untuk pengolahan data pada metode AHP. Software yang digunakan untuk melakukan analisis data adalah Expert Choice (EC). EC adalah suatu program aplikasi yang dapat digunakan sebagai salah satu tool untuk membantu para pengambil keputusan dalam menentukan keputusan. EC menawarkan beberapa fasilitas mulai dari input data-data kriteria, dan beberapa alternatif pilihan, sampai dengan penentuan tujuan. EC mudah dioperasionalkan dengan interface yang sederhana. Kemampuan lain yang disediakan adalah mampu melakukan analisis secara kuantitatif dan kualitatif sehingga hasilnya rasional. Didukung dengan gambar grafik dua dimensi membuat EC semakin menarik. EC didasarkan pada metode/ proses hirarki analitik (Analytic Hierarchi Process/AHP).

\section{g. Pengolahan Data dan Analisis Data}

Menurut Kadarsyah dan Ali (1998) dalam (Munthafa \& Mubarok, 2017), langkah- langkah yang dilakukan dalam metode AHP sebagai berikut:

1. Mendefinisikan masalah dan menentukan solusi yang diinginkan.

2. Membuat struktur hierarki yang diawali dengan tujuan utama.

3. Membuat matrik perbandingan berpasangan yang menggambarkan kontribusi relatif atau pengaruh setiap elemen terhadap tujuan atau kriteria yang setingkat di atasnya.

4. Mendefinisikan perbandingan berpasangan sehingga diperoleh jumlah penilai seluruhnya sebanyak $\mathrm{n} \times[(\mathrm{n}-1) / 2]$ buah, dengan $\mathrm{n}$ adalah banyaknya elemen yang dibandingkan.

Tabel 1. Skala penilaian perbandingan berpasangan

\begin{tabular}{cc}
\hline $\begin{array}{c}\text { Itensitas } \\
\text { Kepentingan }\end{array}$ & Keterangan \\
\hline 1 & Kedua elemen sama penting \\
3 & Elemen yang satu sedikit lebih penting dari elemen lainnya \\
5 & Elemen yang satu lebih penting dari elemen lainnya \\
7 & Elemen yang satu sangat penting dari elemen lainnya \\
9 & Elemen yang satu mutlak sangat penting dari elemen lainnya \\
$2,4,6,8$ & Nilai-nilai antaradua nilai pertimabangan yang berdekatan \\
Kebalikan & Jika aktivitas i mendapat satu angka dibandingkan dengan aktivitas $\mathrm{j}$, maka $\mathrm{j}$ \\
& memiliki nilai kebalikan dibandingkan i \\
\hline
\end{tabular}

5. Menghitung nilai eigen dan menguji konsistensinya. Jika tidak konsisten maka pengambilan data diulangi.

6. Mengulangi langkah 3,4, dan 5 untuk seluruh tingkat hierarki.

7. Menghitung vektor eigen dari setiap matriks perbandingan berpasangan yang merupakan bobot setiap elemen untuk penentuan prioritas elemen-elemen pada tingkat hierarki terendah sampai mencapai tujuan. Penghitungan dilakukan lewat cara menjumlahkan nilai setiap kolom yang bersangkutan untuk memperoleh normalisasi matriks, dan menjumlahkan nilainilai dari setiap baris dan membaginya dengan jumlah elemen untuk mendapatkan rata-rata. Apabila A adalah matriks perbandingan berpasangan, maka vektor bobot yang berbentuk:

$$
(A)\left(w^{T}\right)=(n)\left(W^{T}\right)
$$

dapat didekati dengan cara:

- Menormalkan setiap kolom j dalam matriks A, sedemikian hingga:

$\sum_{i} a(i, j)=1$ 
sebut sebagai A'.

- Hitung nilai rata-rata untuk setiap baris i dalam A':

$w_{i}=\frac{1}{n} \sum_{i} a(i, j)$

dengan $w_{i}$ adalah bobot tujuan ke-i dari vektor bobot.

8. Memeriksa konsistensi hirarki.

Misal A adalah matriks perbandingan berpasangan dan w adalah vektor bobot, maka konsistensi dari vektor bobot $\mathrm{w}$ dapat diuji sebagai berikut:

- Hitung Konsistensi dari Vektor Bobot: $(A)\left(w^{T}\right)$

$t=\frac{1}{n} \sum_{i=1}^{n}\left(\frac{\text { elemen } k e-i \text { pada }(A)\left(w^{T}\right)}{\text { elemen } k e-i \text { pada }\left(w^{T}\right)}\right)$

- Hitung indeks konsistensi:

$C I=\frac{t-n}{n-1}$

- Indeks random $\mathrm{RI}_{n}$ adalah nilai rata-rata $\mathrm{CI}$ yang dipilih secara acak pada A dan diberikan sebagai:

\begin{tabular}{cccccccc}
\hline $\mathrm{n}$ & 2 & 3 & 4 & 5 & 6 & 7 & $\ldots$ \\
\hline $\mathrm{RI}_{\mathrm{n}}$ & 0 & 0,58 & 0,90 & 1,12 & 1,24 & 1,32 & $\ldots$ \\
\hline
\end{tabular}

- Hitung rasio konsistensi

$$
C R=\frac{C I}{R I_{n}}
$$

- Jika $\mathrm{CR}=0$, maka hierarki konsisten

- Jika CR $<0,1$, maka hierarki cukup konsisten

- Jika CR $>0,1$, maka hierarki sangat tidak konsisten)

\section{h. Pengolahan Data dan Analisis Data}

Pada sub bab ini akan dibahas mengenai variabel dan alternatif yang digunakan dalam membuat kuesioner AHP yang diberikan kepada responden. Tahap identifikasi kriteria dan Alternatif mengacu pada beberapa penelitian antara lain Chang \& Cheng (2019) dan Singha, et al., (2016). Berdasarkan studi literatur penelitian tersebut maka ditentukan alternatif-alternatif yang berkaitan dengan sustainability pada IKM. Kriteria-kriterianya ditunjukkan pada Tabel 2.

Tabel 2. Kriteria dan Alternatif

\begin{tabular}{|c|c|c|}
\hline Kriteria & Alternatif & Referensi \\
\hline \multirow{6}{*}{ Sosial (S) } & Meningkatkan kesempatan kerja masyarakat local (S1) & \multirow{18}{*}{$\begin{array}{c}\text { (Chang \& } \\
\text { Cheng, 2019) } \\
\text { (Singha , } \\
\text { Olugua, \& } \\
\text { Nurma, 2016) }\end{array}$} \\
\hline & Pelatihan di lingkungan karyawan (S2) & \\
\hline & Kebijakan ketenagakerjaan (S3) & \\
\hline & Kesehatan dan keselamatan (S4) & \\
\hline & Umpan balik masyarakat setempat (S5) & \\
\hline & Keluhan atau pengembalian pelanggan (S6) & \\
\hline \multirow{6}{*}{ Lingkungan $(\mathrm{L})$} & Kurangi penggunaan bahan baku yang berbahaya (L1) & \\
\hline & Kurangi penggunaan energi (L2) & \\
\hline & Mengurangi emisi gas rumah kaca (L3) & \\
\hline & Desain produk go green (L4) & \\
\hline & Meningkatkan penggunaan energi hijau (L5) & \\
\hline & Penggunaan bangunan dengan prinsip go green (L6) & \\
\hline \multirow{6}{*}{ Ekonomi (E ) } & Biaya produk $(\mathrm{E} 1)$ & \\
\hline & Biaya pemesanan dan biaya logistic (E2) & \\
\hline & Pengiriman tepat waktu (E3) & \\
\hline & Kemampuan desain produk dan riset pasar (E4) & \\
\hline & Transparansi dan akuntabilitas perusahaan (E5) & \\
\hline & Keuntungan (E6) & \\
\hline
\end{tabular}




\section{HASIL DAN PEMBAHASAN}

Pada subbab ini akan dijelaskan mengenai pengolahan data berdasarkan tingkat kepentingan. Hasil kuesioner yang telah diisi oleh expert kemudian di olah dengan menggunakan AHP untuk mengetahui tingkat kepentingan dari masing-masing kriteria dan alternatif yang terdiri dari beberapa indikator. Pengolahan data dilakukan dengan software Expert Choice.

\section{a. Penentuan Tujuan Pengambilan Keputusan berdasarkan AHP}

Berikut ini adalah pengambilan keputusan untuk menentukan tingkat kepentingan dari setiap kriteria yang perlu dipertimbangkan dalam menentukan "tujuan pengambilan keputusan". Berikut adalah gambar yang menunjukkan tujuan, kriteria, dan indikator pada alternatif.

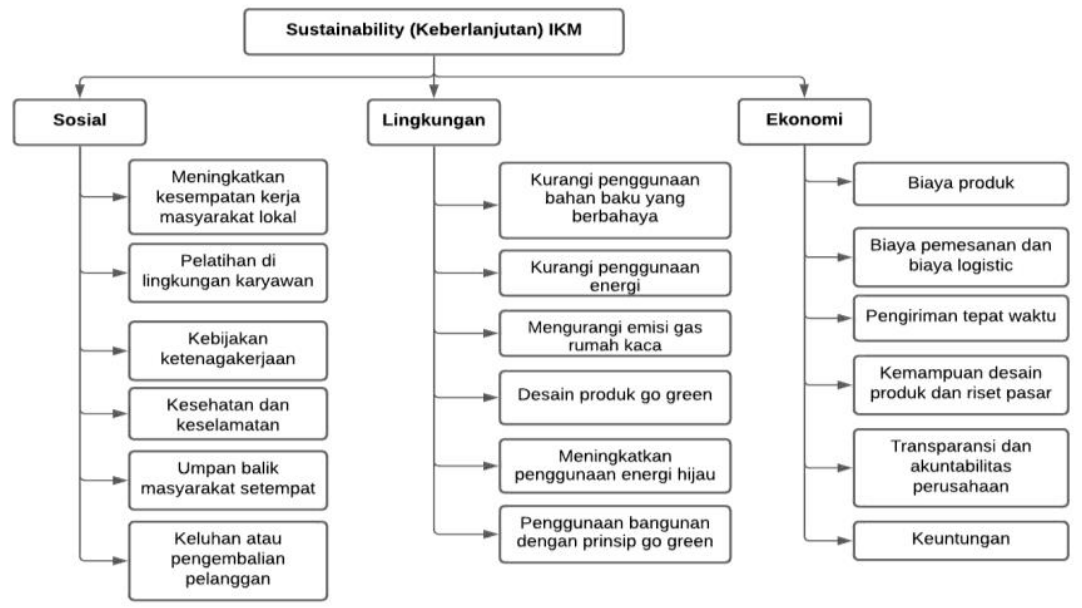

Gambar 1. Tujuan Pengambilan Keputusan

\section{b. Penentuan Posisi dari Setiap Kriteria}

Pada tahap ini adalah menentukan posisi dari setiap kriteria berdasarkan kuesioner AHP yang telah dibagikan. Pada Tabel 3 menunjukkan hasil bobot dari setiap kriteria sustainability.

Tabel 3. Pembobotan Kriteria

\begin{tabular}{lccc}
\hline \multicolumn{1}{c}{ Kriteria } & Ekonomi $(\mathrm{E})$ & Sosial $(\mathrm{S})$ & Lingkungan $(\mathrm{L})$ \\
\hline Ekonomi $(\mathrm{E})$ & 1,00 & 3,00 & 5,00 \\
\hline Sosial $(\mathrm{S})$ & 0,33 & 1,00 & 3,00 \\
\hline Lingkungan $(\mathrm{L})$ & 0,20 & 0,33 & 1,00 \\
\hline Jumlah & 1,53 & 4,33 & 9,00 \\
\hline
\end{tabular}

Berikut adalah tabel hasil normalisasi dengan menentukan priority vector dan dilakukan uji konsistensi pada masing-masing bobot kriteria. Tujuan melakukan uji konsistensi adalah untuk Untuk memastikan kekonsistenan pengguna dalam memasukkan perbandingan yang berpengaruh terhadap hasil akhir, selain itu juga dilakukan untuk proses pengecekan terhadap konsistensi setiap perbandingan.

Tabel 4. Uji Konsistensi Kriteria

\begin{tabular}{lccccc}
\hline \multicolumn{1}{c}{ Kriteria } & Ekonomi & Sosial & Lingkungan & Priority Vector & Uji Konsistensi \\
\hline Ekonomi & 0,65 & 0,69 & 0,56 & 0,63 & 1,95 \\
\hline Sosial & 0,22 & 0,23 & 0,33 & 0,26 & 0,79 \\
\hline Lingkungan & 0,13 & 0,08 & 0,11 & 0,11 & 0,32 \\
\hline Jumlah & 1,00 & 1,00 & 1,00 & 1,00 & 3,06 \\
\hline
\end{tabular}


Berdasarkan hasil perhitungan priority vector maka diperoleh nilai priority yang tertinggi dari tiga kriteria adalah ekonomi yaitu 0,63 . Begitu juga dengan uji konsistensi yang dilakukan menunjukkan nilai tertinggi pada kriteria ekonomi yaitu 1,95.

Untuk menentukan nilai lambda maka terlebih daruhu dilakukan perhitungan dengan membagi antara nilai uji konsistensi dengan priority vector, kemuadia merata-ratakan hasilnya. Nilai lambda ditunjukkan pada Tabel 5.

Tabel 5. Nilai Lambda

\begin{tabular}{lc}
\hline \multicolumn{1}{c}{ Kriteria } & Priority vector/ Uji konsistensi \\
\hline Ekonomi & 3,07 \\
Sosial & 3,03 \\
Lingkungan & 3,01 \\
Nilai Lambda (Rata-rata) & 3,04 \\
\hline
\end{tabular}

Dari nilai lambda kemudian diketahui nilai $C I, R I$, dan $C R$ yang bertujuan untuk mengetahui tingkat konsistensi dari nilai pembobotan yang telah ditentukan berdasarkan kuesioner. Berdasarkan persamaan (4) sampai (6), didapat nilai $C I, R I$, dan $C R$ masing-masing sebesar 0,02, 0,66, dan 0,03. Dengan nilai $C R$ tersebut $(0,03)$, maka hirarki menunjukkan cukup konsisten.

\section{c. Penentuan Posisi dari Setiap Alternatif}

Alternatif ditentukan berdasarkan indikator pada masing-masing kriteria yaitu ekonomi, sosial, dan lingkungan. Masing-masing kriteria terdiri dari enam indikator yang juga dilakukan pembobotan kepentingan.

\section{1) Kriteria Sosial}

Tabel 6 adalah nilai hasil pembobotan untuk alternatif berdasarkan kriteria sosial yang terdiri dari enam alternatif.

Tabel 6. Pembobotan Alternatif Kriteria Sosial

\begin{tabular}{cccrrrr}
\hline Alternatif & S1 & S2 & S3 & S4 & \multicolumn{1}{c}{ S5 } & \multicolumn{1}{c}{ S6 } \\
\hline S1 & 1,00 & 3,00 & 1,00 & 0,33 & 3,00 & 3,00 \\
S2 & 0,33 & 1,00 & 3,00 & 0,33 & 3,00 & 1,00 \\
S3 & 1,00 & 0,33 & 1,00 & 0,33 & 3,00 & 3,00 \\
S4 & 3,00 & 3,00 & 3,00 & 1,00 & 4,00 & 4,00 \\
S5 & 0,33 & 0,33 & 0,33 & 0,25 & 1,00 & 1,00 \\
S6 & 0,33 & 1,00 & 0,33 & 0,25 & 1,00 & 1,00 \\
Jumlah & 6,00 & 8,67 & 8,67 & 2,50 & 15,00 & 13,00 \\
\hline
\end{tabular}

Tabel 7 adalah tabel hasil normalisasi dengan menentukan priority vector dan dilakukan uji konsistensi pada masing-masing bobot alternatif pada kriteria sosial.

Tabel 7. Uji Konsistensi Alternatif Kriteria Sosial

\begin{tabular}{ccccccccc}
\hline Alternatif & S1 & S2 & S3 & S4 & S5 & S6 & Priority Vector & Uji Konsistensi \\
\hline S1 & 0,17 & 0,35 & 0,12 & 0,13 & 0,20 & 0,23 & 0,20 & 1,34 \\
S2 & 0,06 & 0,12 & 0,35 & 0,13 & 0,20 & 0,08 & 0,15 & 1,05 \\
S3 & 0,17 & 0,04 & 0,12 & 0,13 & 0,20 & 0,23 & 0,15 & 0,93 \\
S4 & 0,50 & 0,35 & 0,35 & 0,40 & 0,27 & 0,31 & 0,36 & 2,42 \\
S5 & 0,06 & 0,04 & 0,04 & 0,10 & 0,07 & 0,08 & 0,06 & 0,40 \\
S6 & 0,06 & 0,12 & 0,04 & 0,10 & 0,07 & 0,08 & 0,08 & 0,50 \\
Jumlah & 1,00 & 1,00 & 1,00 & 1,00 & 1,00 & 1,00 & 1,00 & 6,63 \\
\hline
\end{tabular}

Berdasarkan hasil perhitungan priority vector maka diperoleh nilai priority yang tertinggi dari enam alternatif pada kriteria sosial adalah S4 (Kesehatan dan Keselamatan) yaitu 0,36. 
Begitu juga dengan uji konsistensi yang dilakukan menunjukkan nilai tertinggi pada S4 yaitu 2,42 .

Nilai Lambda berdasarkan alternatif pada kriteria sosial adalah ditunjukkan pada Tabel 8 .

Tabel 8. Nilai Lambda Alternatif Kriteria Sosial

\begin{tabular}{cc}
\hline Alternatif & Priority vector/ Uji konsistensi \\
\hline S1 & 6,77 \\
S2 & 6,77 \\
S3 & 6,33 \\
S4 & 6,69 \\
S5 & 6,31 \\
S6 & 6,60 \\
Nilai Lambda (Rata-rata) & 6,58 \\
\hline
\end{tabular}

Dari nilai lambda kemudian didapat nilai CI, RI, dan CR masing-masing 0,12, 1,32, dan 0,09. Karena nilai $C R<0,1$. Yaitu 0,09 maka hirarki dianggap cukup konsisten untuk alternatif pada kriteria sosial.

\section{2) Kriteria Lingkungan}

Tabel 9 meninjukkan nilai hasil pembobotan untuk alternatif berdasarkan kriteria lingkungan yang terdiri dari enam alternatif.

Tabel 9. Pembobotan Alternatif Kriteria Lingkungan

\begin{tabular}{ccccccc}
\hline Alternatif & L1 & L2 & L3 & L4 & L5 & L6 \\
\hline L1 & 1,00 & 0,20 & 0,25 & 0,33 & 0,20 & 0,25 \\
L2 & 5,00 & 1,00 & 5,00 & 4,00 & 3,00 & 3,00 \\
L3 & 4,00 & 0,20 & 1,00 & 2,00 & 0,50 & 0,50 \\
L4 & 3,00 & 0,25 & 0,50 & 1,00 & 0,25 & 0,33 \\
L5 & 5,00 & 0,33 & 2,00 & 4,00 & 1,00 & 1,00 \\
L6 & 4,00 & 0,33 & 2,00 & 3,00 & 1,00 & 1,00 \\
Jumlah & 22,00 & 2,31 & 10,75 & 14,33 & 5,95 & 6,08 \\
\hline
\end{tabular}

Tabel 10 menunjukkan hasil normalisasi dengan menentukan priority vector dan dilakukan uji konsistensi pada masing-masing bobot alternatif pada kriteria lingkungan.

Tabel 10. Uji Konsistensi Alternatif Kriteria Lingkungan

\begin{tabular}{ccccccccc}
\hline Alternatif & L1 & L2 & L3 & L4 & L5 & L6 & Priority Vector & Uji Konsistensi \\
\hline L1 & 0,05 & 0,09 & 0,02 & 0,02 & 0,03 & 0,04 & 0,04 & 0,26 \\
L2 & 0,23 & 0,43 & 0,47 & 0,28 & 0,50 & 0,49 & 0,40 & 2,58 \\
L3 & 0,18 & 0,09 & 0,09 & 0,14 & 0,08 & 0,08 & 0,11 & 0,70 \\
L4 & 0,14 & 0,11 & 0,05 & 0,07 & 0,04 & 0,05 & 0,08 & 0,46 \\
L5 & 0,23 & 0,14 & 0,19 & 0,28 & 0,17 & 0,16 & 0,19 & 1,24 \\
L6 & 0,18 & 0,14 & 0,19 & 0,21 & 0,17 & 0,16 & 0,18 & 1,12 \\
Jumlah & 1,00 & 1,00 & 1,00 & 1,00 & 1,00 & 1,00 & 1,00 & 6,37 \\
\hline
\end{tabular}

Berdasarkan hasil perhitungan priority vector maka diperoleh nilai priority yang tertinggi dari enam alternatif pada kriteria lingkungan adalah L2 (kurangi penggunaan energi) yaitu 0,40. Begitu juga dengan uji konsistensi yang dilakukan menunjukkan nilai tertinggi pada L4 yaitu 2,58 .

Nilai Lambda berdasarkan alternatif pada kriteria lingkungan ditunjukkan pada Tabel 11. Dari nilai lambda kemudian didapat nilai CI, RI, dan CR masing-masing 0,06, 1,32, dan 0,04. Karena nilai $\mathrm{CR}<0,1$. Yaitu 0,04 maka hirarki dianggap cukup konsisten untuk alternatif pada kriteria lingkungan. 
Tabel 11. Nilai Lambda Alternatif Kriteria Lingkungan

\begin{tabular}{cc}
\hline Alternatif & Priority vector/ Uji konsistensi \\
\hline L1 & 6,12 \\
L2 & 6,45 \\
L3 & 6,27 \\
L4 & 6,10 \\
L5 & 6,37 \\
L6 & 6,39 \\
Nilai Lambda (Rata-rata) & 6,29 \\
\hline
\end{tabular}

\section{3) Kriteria Ekonomi}

Tabel 12 menunjukkan hasil pembobotan untuk alternatif berdasarkan kriteria ekonomi yang terdiri dari enam alternatif.

Tabel 12. Pembobotan Alternatif Kriteria Ekonomi

\begin{tabular}{ccccccc}
\hline Alternatif & E1 & E2 & E3 & E4 & E5 & E6 \\
\hline E1 & 1,00 & 0,33 & 0,33 & 0,33 & 1,00 & 0,14 \\
E2 & 3,00 & 1,00 & 1,00 & 3,00 & 3,00 & 0,20 \\
E3 & 3,00 & 1,00 & 1,00 & 5,00 & 5,00 & 0,20 \\
E4 & 3,00 & 0,33 & 0,20 & 1,00 & 1,00 & 0,20 \\
E5 & 1,00 & 0,33 & 0,20 & 1,00 & 1,00 & 0,14 \\
E6 & 7,00 & 5,00 & 5,00 & 5,00 & 7,00 & 1,00 \\
Jumlah & 18,00 & 8,00 & 7,73 & 15,33 & 18,00 & 1,89 \\
\hline
\end{tabular}

Tabel 13 menunjukkan hasil normalisasi dengan menentukan priority vector dan dilakukan uji konsistensi pada masing-masing bobot alternatif pada kriteria ekonomi.

Tabel 13. Uji Konsistensi Alternatif Kriteria Ekonomi

\begin{tabular}{cllllllcc}
\hline Alternatif & E1 & E2 & E3 & E4 & E5 & E6 & Priority Vector & Uji Konsistensi \\
\hline E1 & 0,06 & 0,04 & 0,04 & 0,02 & 0,06 & 0,08 & 0,05 & 0,31 \\
E2 & 0,17 & 0,13 & 0,13 & 0,20 & 0,17 & 0,11 & 0,15 & 0,97 \\
E3 & 0,17 & 0,13 & 0,13 & 0,33 & 0,28 & 0,11 & 0,19 & 1,23 \\
E4 & 0,17 & 0,04 & 0,03 & 0,07 & 0,06 & 0,11 & 0,08 & 0,46 \\
E5 & 0,06 & 0,04 & 0,03 & 0,07 & 0,06 & 0,08 & 0,05 & 0,34 \\
E6 & 0,39 & 0,63 & 0,65 & 0,33 & 0,39 & 0,53 & 0,48 & 3,27 \\
Jumlah & 1,00 & 1,00 & 1,00 & 1,00 & 1,00 & 1,00 & 1,00 & 6,57 \\
\hline
\end{tabular}

Berdasarkan hasil perhitungan priority vector maka diperoleh nilai priority yang tertinggi dari enam alternatif pada kriteria ekonomi adalah E6 (keuntungan) yaitu 0,48. Begitu juga dengan uji konsistensi yang dilakukan menunjukkan nilai tertinggi pada L4 yaitu 3,27. Nilai Lambda berdasarkan alternatif pada kriteria ekonomi adalah ditunjukkan pada Tabel 14.

Tabel 14. Nilai Lambda Alternatif Kriteria Ekonomi

\begin{tabular}{cc}
\hline Alternatif & Priority vector/ Uji konsistensi \\
\hline E1 & 6,32 \\
E2 & 6,55 \\
E3 & 6,53 \\
E4 & 6,00 \\
E5 & 6,29 \\
E6 & 6,75 \\
Nilai Lambda (Rata-rata) & 6,41 \\
\hline
\end{tabular}

Dari nilai lambda kemudian didapat nilai CI, RI, dan CR masing-masing 0,08, 1,32, dan 0,06. Karena nilai $\mathrm{CR}<0,1$, yaitu 0,06 maka hirarki dianggap cukup konsisten untuk alternatif pada kriteria ekonomi. 


\section{d. Analisis Pengumpulan Data}

Dalam penelitian ini data dikumpulkan dengan pembagian kuesioner secara offline. Adapun tujuan dilakukan penyebaran kuesioner secara offline agar responden dapat dikontrol saat melakukan pengisian kuesioner. Untuk penilaian kuesioner menggunakan pembobotan AHP. Adapun arti dari nilai tersebut adalah menunjukkan tingkat kepentingan dari kriteria atau alternatif pada sustainability IKM. Adapun karasteristik responden yang digunakan pada kuesioner yang disebar adalah responden yang merupakan expert/ ahli dalam bidang IKM khususnya di kota Makassar yang dibuktikan dengan pengalaman-pengalaman yang diperoleh sangat banyak berkaitan dengan UMKM/ IKM. Melalui kuesioner yang disebar ingin diketahui pandangan para responden tentang kondisi sustainability IKM selama masa pandemi Covid-19. Hasil dari kuesioner kemudian diolah dengan AHP.

\section{e. Analisis Pengolahan Analytical Hierarchi Process (AHP)}

Pada bagian ini akan dijelaskan mengenai analisis AHP yang telah dilakukan pada masingmasing kriteria dan alternatif, analisis dilakukan untuk mengetahui kriteria sustainability yang memiliki tingkat kepentingan yang paling tinggi dan paling terkena dampak karena pandemi Covid-19. Sama halnya dengan alternatif pada setiap kriteria juga dilakukan analisis untuk mengetahui alternatif dari masing-masing kriteria yang paling tinggi tingkat kepentingannya dan terkena dampak karena pandemi Covid-19.

\section{1) Analisis Kriteria pada AHP}

Kriteria AHP terdiri dari kriteria sosial, lingkungan, dan ekonomi. Masing-masing kriteria diberi pembobotan dengan membandingkan antara kriteria satu dengan yang lain, pembobotan berdasarkan kriteria yang lebih penting dibandingkan dengan kriteria yang lainnya. Dari hasil penilaian dengan pembobotan AHP maka diperoleh nilai tingkat kepentingan tertinggi antara ketiga kriteria. Nilai tertinggi adalah kriteria ekonomi dengan nilai priority vector sebesar 0,63. Nilai pada kriteria sosial adalah 0,26 dan nilai pada kriteria lingkungan adalah 0,11 . Dengan demikian, kriteria ekonomi memiliki tingkat kepentingan paling tinggi dibandingkan kriteria yang lain. Masa pandemi Covid-19 diketahui mempengaruhi beberapa sector, salah satunya adalah perekonomian. Melalui penelitian yang dilakukan dengan AHP maka dapat dikatakan bahwa aspek sustainability IKM yang paling terdampak pandemi Covid-19 adalah bidang ekonomi. Untuk menguji kekonsistenan dari pembobotan AHP yang dilakukan maka dibuat perhitungan uji konsistensi dengan menghitung nilai lambda, CI, RI, dan CR. Nilai CR yang diperoleh dari pembobotan kriteria adalah 0,03 . Karena nilai CR menunjukkan kurang dari 0,1 maka dapat disimpulkan bahwa hirarki kriteria dianggap cukup konsisten.

\section{2) Analisis Alternatif pada Kriteria Sosial}

Setiap Kriteria AHP terdiri dari beberapa alternatif. Masing-masing alternatif diberi pembobotan dengan membandingkan antara alternatif satu dengan yang lain, pembobotan berdasarkan alternatif yang lebih penting dibandingkan dengan alternatif yang lainnya. Dari hasil penilaian dengan pembobotan AHP berdasarkan alternatif pada kriteria sosial maka diperoleh nilai tingkat kepentingan tertinggi dari enam alternatif. Nilai tertinggi adalah alternatif S4 (Kesehatan dan Keselamatan) dengan nilai priority vector sebesar 0,36. Dengan demikian, dapat dikatakan bahwa kesehatan dan keselamatan pada kriteria sosial merupakan aspek pada IKM yang sangat terkena dampak akibat pandemi Covid-19. Pada dasarnya pandemi Covid-19 memang dapat berpengaruh kuat terhadap Kesehatan dan keselamatan pelaku IKM karena diketahui virus Covid-19 yang memiliki peluang menular sangat tinggi jika tidak dipatuhi protokol Kesehatan yang telah ditetapkan. Oleh karena itu, para pelaku IKM harus mematuhi protokol Kesehatan dalam menjalankan usahanya demi menjamin Kesehatan dan keselamatan para pekerja maupun pemilik IKM itu sendiri. Untuk menguji kekonsistenan dari pembobotan AHP berdasarkan alternatif pada kriteria sosial maka dibuat perhitungan uji konsistensi dengan menghitung nilai lambda, CI, RI, dan CR. Nilai CR yang diperoleh dari pembobotan alternatif 
adalah 0,09. Karena nilai CR menunjukkan kurang dari 0,1 maka dapat disimpulkan bahwa hirarki alternatif untuk kriteria sosial dianggap cukup konsisten.

\section{3) Analisis Alternatif pada Kriteria Lingkungan}

Dari hasil penilaian dengan pembobotan AHP berdasarkan alternatif pada kriteria lingkungan maka diperoleh nilai tingkat kepentingan tertinggi dari enam alternatif. Nilai tertinggi adalah alternatif L2 (kurangi penggunaan energi) dengan nilai priority vector sebesar 0,40. Dengan demikian, dapat dikatakan bahwa kurangi penggunaan energi pada kriteria lingkungan merupakan aspek pada IKM yang sangat terkena dampak akibat pandemi Covid-19. Penggunaan energi yang berlebih dapat memberi dampak terhadap lingkungan. Oleh karena itu, saat ini pemerintah banyak mengeluarkan kebijakan terkait dengan pengurangan dalam penggunaan energi khususnya pada para pelaku usaha termasuk IKM. Jika dihubungkan dengan pandemi Covid-19, maka kondisi pandemi saat ini memiliki peluang besar yang mengakibatkan terjadinya krisis energi. Oleh karena itu, para pelaku IKM harus memperhatikan aspek penggunaan energi dalam menjalankan usahanya agar tetap bertahan ditengah pandemi Covid19. Untuk menguji kekonsistenan dari pembobotan AHP berdasarkan alternatif pada kriteria lingkungan maka dibuat perhitungan uji konsistensi dengan menghitung nilai lambda, CI, RI, dan CR. Nilai CR yang diperoleh dari pembobotan alternatif adalah 0,04. Karena nilai CR menunjukkan kurang dari 0,1 maka dapat disimpulkan bahwa hirarki alternatif untuk kriteria lingkungan dianggap cukup konsisten.

\section{4) Analisis Alternatif pada Kriteria Ekonomi}

Dari hasil penilaian dengan pembobotan AHP berdasarkan alternatif pada kriteria ekonomi maka diperoleh nilai tingkat kepentingan tertinggi dari enam alternatif. Nilai tertinggi adalah alternatif E6 (keuntungan) dengan nilai priority vector sebesar 0,48. Dengan demikian, dapat dikatakan bahwa keuntungan pada kriteria ekonomi merupakan aspek pada IKM yang sangat terkena dampak akibat pandemi Covid-19. Sektor ekonomi merupakan sektor yang mengalami kemerosotan selama pandemi Covid-19, begitu juga pada IKM yang berusaha tetap bertahan dimasa pandemi sebagian besar mengalami kemerosotan dalam bidang ekonomi khususnya terkait keuntungan, kurangnya permintaan atas produk yang dihasilkan menyebabkan penurunan profit atau keuntungan bagi IKM. Untuk menguji kekonsistenan dari pembobotan AHP berdasarkan alternatif pada kriteria ekonomi maka dibuat perhitungan uji konsistensi dengan menghitung nilai lambda, CI, RI, dan CR. Nilai CR yang diperoleh dari pembobotan alternatif adalah 0,06. Karena nilai CR menunjukkan kurang dari 0,1 maka dapat disimpulkan bahwa hirarki alternatif untuk kriteria ekonomi dianggap cukup konsisten.

\section{f. Implikasi Manajerial}

Penelitian ini menemukan bahwa untuk masing-masing kriteria yaitu ekonomi, sosial, dan lingkungan yang memiliki bobot kepentingan tertinggi adalah ekonomi. Hal ini menandakan bahwa usulan kebijakan terkait ekonomi pada IKM pada masa pandemi Covid-19 agar IKM tersebut tetap dapat bertahan adalah dengan memberikan bantuan modal bagi para pelaku IKM yang mengalami kemerosotan ekonomi, selain itu, memberikan fasilitas dalam hal pemasaran produk tanpa harus melanggar aturan pemerintah terkait protokol Kesehatan, mengeluarkan kebijakan yang dapat meningkatkan daya beli masyarakat terhadap produk lokal agar para pelaku IKM tetap dapat menjalankan produksinya walaupun berada pada masa pendemi.

Berdasarkan hasil penelitian yang telah dilakukan maka dapat dirumuskan suatu konsep implikasi manajerial yang dapat digunakan untuk meningkatkan efektivitas dari masing-masing alternatif yang memiliki nilai kepentingan yang paling tinggi. Berikut adalah usulan kebijakan yang dapat dilakukan oleh para pelaku IKM agar tetap bertahan dimasa pandemi Covid-19:

1. Kesehatan dan Keselamatan

Hal yang dapat dilakukan adalah dengan melakukan sosialisasi yang lebih intens kepada para pelaku IKM agar tetap menjaga dan mempertahankan Kesehatan dan keselamatan kerja dalam menjalankan usahanya dengan menerapkan aturan protokol Covid-19 dan terkait 
aturan jadwal masuk kerja berdasarkan status zona Covid-19 tempat IKM tersebut berlokasi. Khususnya dalam hal Kesehatan, kondisi pandemi Covid-19 menuntut kita agar lebih berhati-hati dalam menjaga Kesehatan. Oleh karena itu, walaupun para IKM tetap menjalankan produksinya akan tetapi jangan sampai lalai dalam hal Kesehatan dan keselamatan bagi para pekerja dan pemilik IKM itu sendiri.

2. Kurangi Penggunaan Energi

Hal yang dapat dilakukan untuk mendukung pengurangan dalam hal penggunaan energi adalah dengan menerapkan prinsip lean pada proses produksi dan manajemennya. Lean merupakan upaya dalam meminimalisir terjadinya pemborosan termasuk dalam hal penggunaan energi. Sistem produksi ramping ini dapat mengurangi akitivitas-aktivitas yang dianggap tidak memberi nilai bagi produk atau manajemen. Langkah lean dapat dilakukan dengan cara mengidentifikasi aktivitas yang memebutuhkan energi baik sedikit maupun banya, namun aktivitas tersebut jika dihilangkan tidak mempengaruhi produk yang dihasilkan. Kondisi pandemi Covid-19 berpeluang menyebabkan terjadinya krisis energi. Oleh karena itu, para pelaku IKM harus memiliki strategi yang tepat untuk menghadapi pandemi Covid-19 dalam hal penggunaan energi.

3. Keuntungan

Hal yang dapat dilakukan dengan melihat aspek keuntungan adalah dengan membuat strategi manajemen untuk meningkatkan profit walaupun sedang berhadapan dengan pandemi Covid-19. Strategi manajemen yang dapat diterapkan pada IKM bisa berupa strategi pemasaran secara digital dan strategi dalam hal proses distribusi produk

\section{KESIMPULAN}

Hasil AHP berdasarkan tiga kriteria menunjukkan nilai kepentingan tertinggi adalah pada kriteria ekonomi dengan priority vector sebesar 0.63 . Sedangkan nilai kepentingan tertinggi alternatif pada kriteria sosial pada aspek Kesehatan dan keselamatan dengan priority vector sebesar 0.36, nilai kepentingan tertinggi alternatif pada kriteria lingkungan adalah kurangi penggunaan energi dengan priority vector sebesar 0.40 , sedangkan nilai tertinggi alternatif pada kriteria ekonomi adalah keuntungan dengan priority vector sebesar 0.48 . Uji konsistensi yang dilakukan pada pembobotan kriteria menunjukkan nilai CI kurang dari 0,01 yang berarti hirarki kriteria dianggap cukup konsisten. Uji konsistensi untuk alternatif pada masing-masing kriteria berdasarkan pembobotan menunjukkan nilai CI kurang dari 0,01 yang berarti hirarki alternatif untuk kriteria sosial, lingkungan, dan ekonomi dianggap cukup konsisten. Berdasarkan hasil pembobotan kepentingan tersebut maka dapat diberikan masukan kepada pemerintah maupun kepada pelaku IKM terkait pembuatan kebijakan maupun strategi usaha dalam menghadapi pandemi Covid-19 khususnya pada kriteria sosial yaitu Kesehatan dan keselamatan, kriteria lingkungan yaitu kurangi penggunaan energi, dan kriteria ekomoni yaitu keuntungan.

Pada penelitian selanjutnya sebaiknya dilakukan analisis sensivitas terkait kriteria dan alternatif pada sustainability IKM yang dapat diperoleh dengan menggunakan program Expert Choice.

\section{UCAPAN TERIMA KASIH}

Terima kasih kami ucapkan kepada LP2M Universitas Hasanuddin, para expert dalam bidang IKM, dan seluruh Dosen Departemen Teknik Industri Unhas yang mendukung penulisan artikel ini hingga tahap penyelesaian.

\section{DAFTAR PUSTAKA}

Asmara, A. Y. \& Rahayu, S., 2014. Meningkatkan Daya Saing Industri Kecil Menengah melalui Inovasi dan Pemanfaatan Jaringan Sosial: Pembelajaran dari Klaster Industri Software di India, s.l.: Pappiptek LIPI.

Bell, S \& Morse, S., 2008. Sustainability Indicators: Measuring the Immeasurable? Ed.II. London: Earthscan. 
Chang, A.-Y. \& Cheng, Y.-T., 2019. Analysis model of the sustainability development of manufacturing small and medium- sized enterprises in Taiwan. Journal of Cleaner Production, pp. 458-473.

Erdin, C. \& Ozkaya, G., 2020. Contribution of small and medium enterprises to economic development and quality of life in Turkey. Heliyon.

Leea, C. M. J., Che-Haa, N. \& Alwi, S. F. S., 2019. Service customer orientation and social sustainability: The case of small medium enterprises. Journal of Business Research, pp. 751-760.

Malesios, C. et al., 2020. Sustainability Performance Analysis of Small and Medium Sized Enterprises: Criteria, Methods and Framework Chrisovalantis. Socio-Economic Planning Sciences.

Munthafa, A. E. \& Mubarok, H., 2017. Penerapan Metode Analytical Hierarchy Process dalam Sisitem Pendukung Keputusan Penentuan Mahasiswa Berprestasi. Jurnal Siliwangi, pp. 192-201.

Pakpahan, K. A., 2020. COVID-19 dan Implikasi Bagi Usaha Mikro, Kecil, dan Menengah, Bandung: Universitas Katolik Parahyangan.

Pereira a,, I. P. et al., 2020. A fuzzy cognitive mapping-system dynamics approach to energychange impacts on the sustainability of small and medium-sized enterprises. Journal of Cleaner Production journal, pp. 1-17.

Phan, H. \& Kim, . S., 2019. The effects of sustainable practices and managers' leadership competences on sustainability performance of construction firms. Sustainable Construction and Consumption, pp. 1-14.

Ridwan, M., Hartutiningsih \& Mass'ad , H., 2014. Pembinaan Industri Kecil dan Menengah Pada Dinas Perindustrian, Perdagangan, Koperasi dan UMKM Kota Bontang. Jurnal Administrative Reform, pp. 187-199.

Saaty, T., 1988. The Analytical Hierarchy Process For Decision In Complex World. Pittsburgh: RWS Publication.

Setiyadi, S., Amar, K. \& Aji, T., 2011. Penentuan Strategi Sustainability Usaha pada UKM Kuliner dengan Menggunakan Metode SWOT-AHP. Jurnal Ilmiah Teknik Industri, pp. 68-77.

Singha, S., Olugua, E. U. \& Nurma, S., 2016. Development of sustainable manufacturing performance evaluation expert system for small and medium enterprises. Procedia CIRP, pp. 609-614.

Stopper, M., Kossik, A. \& Gastermann, B., 2016. Development of a sustainability model for manufacturing SMEs based on the innovative doughnut economics framework. Hongkong, s.n.

Tajbakhsh, A. \& Hassini, E., 2015. Performance measurement of sustainable supply chains: a review and research questions. International Journal of Productivity and Performance Management, pp. 744-783.

Witjes, . S., Vermeulen, W. \& Cramer, . J., 2017. Exploring corporate sustainability integration into business activities. Experiences from 18 small and medium sized enterprises in the Netherlands.. Journal of Cleaner Production, pp. 528-538.

Zhang, H., Veltri, A., Amodio, J. C. \& Haapala, K. R., 2020. Making the business case for sustainable manufacturing in small and medium-sized manufacturing enterprises: A systems decision making approach. Journal of Cleaner Production 